\title{
Solubility in Binary Solvent Mixtures: Anthracene Dissolved in Alcohol + Acetonitrile Mixtures at $298.2 \mathrm{~K}$
}

\author{
Cassandra I. Monárrez, J ee H. Woo, Priscilla G. Taylor, Anh M. Tran, and William E. Acree, J r.* \\ Department of Chemistry, P.O. Box 305070, University of North Texas, Denton, Texas 76203-5070
}

\begin{abstract}
Experimental solubilities are reported for anthracene dissolved in six binary alcohol + acetonitrile solvent mixtures at $25^{\circ} \mathrm{C}$. The al cohol cosolvents studied were methanol, ethanol, 1-pentanol, 2-pentanol, 2-methyl1-pentanol, and 4-methyl-2-pentanol. Results of these measurements are used to test a mathematical representation based upon the combined nearly ideal binary solvent (NIBS)/Redlich-Kister equation. For the six systems studied, the combined NIBS/Redlich-Kister equation was found to mathematically describe the experimental data to within an overall average absolute deviation of approximately $\pm 0.7 \%$.
\end{abstract}

\section{Introduction}

Solid-liquid equilibrium data of organic nonelectrolyte systems are becoming increasingly important in the petroleum industry, particularly in light of present trends toward heavier feedstocks and known carcinogenicity/ mutagenicity of many of the larger polycyclic aromatic compounds. Solubility data for a number of polycyclic aromatic hydrocarbons (i.e., anthracene and pyrene) and heteroatom polynuclear aromatics (i.e., carbazole, dibenzothiophene, and xanthene) have been published in the recent chemical literature (for listing of references see refs 1-3). Despite efforts by experimentalists and scientific organizations, both in terms of new experimental measure ments and critically evaluated data compilations, there still exist numerous systems for which solubility data are not readily available.

To address this problem, researchers have turned to predictive methods as a means to generate desired quantities. Numerous equations have been suggested for predicting solute solubilities in binary solvent mixtures. For the most part, the predictive methods do provide fairly reasonable estimates for noncomplexing systems. There still remains, however, the need to develop better predictive expressions and mixing models to describe the more nonideal complexing systems believed to contain hydrogen bonding solvent components. Continued development of solution models for describing the thermodynamic properties of a solute in binary solvent systems requires that a large database be available for assessing the applications and limitations of derived expressions. Currently, only a limited database exists for crystalline nonel ectrolyte solubility in binary solvent mixtures. For this reason, anthracene sol ubilities were determined in six binary al cohol + acetonitrile solvent mixtures. Results of these measurements are used to further test the descriptive ability of the combined nearly ideal binary solvent (NIBS)/RedlichKister equation.

\section{Experimental Methods}

Anthracene (Aldrich, 99\%) was recrystallized threetimes from acetone. Methanol (Aldrich, 99.9+\%), ethanol (Asper Alcohol and Chemical Company, absolute), 1-pentanol (Aldrich, 99+\%), 2-pentanol (Acros, 99+\%), 2-methyl-1-

\footnotetext{
* To whom correspondence should be addressed. E-mail: acree@unt.edu.
}

pentanol (Aldrich, 99+\%), 4-methyl-2-pentanol (Acros, 99+\%), and acetonitrile (Aldrich, 99.8\%, anhydrous) were stored over molecular sieves and distilled shortly before use. Gas chromatographic analysis showed solvent purities to be $99.7 \mathrm{~mol} \%$ or better. Binary solvent mixtures were prepared by mass so that compositions could be calculated to 0.0001 mole fraction.

Excess solute and solvent were placed in amber glass bottles and allowed to equilibrate in a constant temperature water bath at $(25.0 \pm 0.1){ }^{\circ} \mathrm{C}$ with periodic agitation for at least 3 days (often longer). Attainment of equilibrium was verified both by repetitive measurements after a minimum of three additional days and by approaching equilibrium from supersaturation by pre-equilibrating the solutions at a higher temperature. Aliquots of saturated anthracene solutions were transferred through a coarse filter into a tared volumetric flask to determine the amount of sample and diluted quantitatively with methanol for spectrophotometric analysis at $356 \mathrm{~nm}$ on a Bausch and Lomb Spectronic 2000. Concentrations of the dilute solutions were determined from a Beer-Lambert law absorbance versus concentration working curve derived from measured absorbances of standard solutions of known molar concentrations. Apparent molar absorptivities of the nine standard solutions varied systematically with molar concentration and ranged from approximately $\epsilon /\left(\mathrm{L} \mathrm{mol}^{-1}\right.$ $\left.\mathrm{cm}^{-1}\right)=7450$ to $\epsilon /\left(\mathrm{L} \mathrm{mol}^{-1} \mathrm{~cm}^{-1}\right)=7150$ for anthracene concentrations ranging from $\mathrm{C} /\left(\mathrm{mol} \mathrm{L}^{-1}\right)=6.75 \times 10^{-5}$ to $\mathrm{C} /\left(\mathrm{mol} \mathrm{L}^{-1}\right)=2.25 \times 10^{-4}$. I dentical molar absorptivities were obtained for select anthracene standard solutions that contained up to $5 \mathrm{vol} \%$ of the neat alcohol and acetonitrile cosolvents. Experimental anthracene solubilities in the six binary alcohol + acetonitrile solvent mixtures are listed in Table 1. Numerical values represent the average of between four and eight independent determinations, with the measured values being reproducible to within $\pm 1.0 \%$.

\section{Results and Discussion}

Acree and co-workers ${ }^{4-6}$ suggested the combined NIBS/ Redlich-Kister model

$$
\ln x_{A}^{\text {sat }}=\phi_{B}^{\circ} \ln \left(x_{A}^{s a t}\right)_{B}+x_{C}^{\circ} \ln \left(x_{A}^{s a t}\right)_{C}+x_{B}^{\circ} x_{C}^{\circ} \sum_{i=0}^{N} S_{i}\left(x_{B}^{\circ}-x_{C}^{\circ}\right)^{i}
$$


Table 1. Experimental Mole Fraction Solubilities of Anthracene $\left(X_{A}^{\text {sat }}\right)$ in Binary Alcohol (B) + Acetonitrile (C) Solvent Mixtures at $25.0^{\circ} \mathrm{C}$

\begin{tabular}{|c|c|c|c|}
\hline$x_{C}^{\circ}$ & $x_{A}^{\text {sat }}$ & $x_{C}^{\circ}$ & $x_{A}^{\text {sat }}$ \\
\hline \multicolumn{4}{|c|}{ Methanol + Acetonitrile } \\
\hline 0.0000 & 0.000243 & 0.5419 & 0.000627 \\
\hline 0.0979 & 0.000320 & 0.7414 & 0.000735 \\
\hline 0.1674 & 0.000370 & 0.8667 & 0.000778 \\
\hline 0.3437 & 0.000502 & 1.0000 & 0.000830 \\
\hline 0.4429 & 0.000565 & & \\
\hline \multicolumn{4}{|c|}{ Ethanol + Acetonitrile } \\
\hline 0.0000 & 0.000460 & 0.6349 & 0.000961 \\
\hline 0.1363 & 0.000669 & 0.8175 & 0.000924 \\
\hline 0.2231 & 0.000773 & 0.9030 & 0.000880 \\
\hline 0.4283 & 0.000917 & 1.0000 & 0.000830 \\
\hline 0.5316 & 0.000962 & & \\
\hline \multicolumn{4}{|c|}{ 1-Pentanol + Acetonitrile } \\
\hline 0.0000 & 0.001097 & 0.7555 & 0.001750 \\
\hline 0.2022 & 0.001723 & 0.8886 & 0.001288 \\
\hline 0.3421 & 0.002021 & 0.9443 & 0.001065 \\
\hline 0.5734 & 0.002066 & 1.0000 & 0.000830 \\
\hline 0.6662 & 0.001971 & & \\
\hline \multicolumn{4}{|c|}{ 2-Pentanol + Acetonitrile } \\
\hline 0.0000 & 0.000800 & 0.7165 & 0.001792 \\
\hline 0.1955 & 0.001484 & 0.8879 & 0.001300 \\
\hline 0.3448 & 0.001807 & 0.9426 & 0.001090 \\
\hline 0.5837 & 0.001947 & 1.0000 & 0.000830 \\
\hline 0.6773 & 0.001867 & & \\
\hline \multicolumn{4}{|c|}{ 2-Methyl-1-pentanol + Acetonitrile } \\
\hline 0.0000 & 0.000966 & 0.7780 & 0.001816 \\
\hline 0.2110 & 0.001653 & 0.9008 & 0.001291 \\
\hline 0.3755 & 0.002064 & 0.9435 & 0.001095 \\
\hline 0.6179 & 0.002109 & 1.0000 & 0.000830 \\
\hline 0.7071 & 0.001972 & & \\
\hline \multicolumn{4}{|c|}{ 4-Methyl-2-pentanol + Acetonitrile } \\
\hline 0.0000 & 0.000779 & 0.7897 & 0.001631 \\
\hline 0.2136 & 0.001407 & 0.9028 & 0.001265 \\
\hline 0.3425 & 0.001679 & 0.9523 & 0.001059 \\
\hline 0.6078 & 0.001881 & 1.0000 & 0.000830 \\
\hline 0.6793 & 0.001817 & & \\
\hline
\end{tabular}

as a possible mathematical representation for describing how experimental isothermal solubility of a crystalline solute dissolved in a binary solvent mixture varies with binary solvent composition. In eq $1 x_{B}^{\circ}$ and $x_{C}^{\circ}$ refer to the initial mole fraction composition of the binary solvent calculated as if solute (A) were not present, $\mathrm{N}$ is the number of curve-fit parameters used, and $\left(x_{A}^{\text {sat }}\right)_{i}$ is the saturated mole fraction solubility of the solute in pure solvent $i$. The various $S_{i}$ "curve-fit" parameters can be evaluated via leastsquares analysis.

The combined NIBS/Redlich-Kister equation has been shown to provide very accurate mathematical representations of anthracene, pyrene, and carbazole solubilities in a large number of both complexing and noncomplexing solvent mixtures. ${ }^{1-3}$ J ouyban-Gharamaleki and coworkers ${ }^{7-10}$ successfully used the volume fraction, $\phi_{\text {, }}$, modification of eq 1

$\ln x_{A}^{\text {sat }}=\phi_{B}^{\circ} \ln \left(x_{A}^{\text {sat }}\right)_{B}+\phi_{C}^{\circ} \ln \left(x_{A}^{\text {sat }}\right)_{C}+\phi_{B}^{\circ} \phi_{C}^{\circ} \sum_{i=0}^{N} S_{i}\left(\phi_{B}^{\circ}-\phi_{C}^{\circ}\right)^{i}$

to describe the solubility behavior of various drug molecules in binary aqueous-organic solvent mixtures. In the pharmaceutical industry, researchers often express the solvent composition in terms of volume fractions, rather than in terms of mole fractions. In the case of structurally similar drug molecules, the numerical values of the $S_{i}$ coefficients were found to be nearly constant in a given binary solvent
Table 2. Mathematical Representation of Anthracene Solubilities in Several Binary Alcohol (B) + Acetonitrile (C) Solvent Mixtures by Eq 1

\begin{tabular}{lrc}
\hline \multirow{2}{*}{ binary solvent system } & \multicolumn{2}{c}{ eq 1 } \\
\cline { 2 - 3 } component B + component C & $\mathrm{S}^{{ }^{a}}$ & $\% \mathrm{dev}^{b}$ \\
\hline methanol + acetonitrile & 1.170 & 0.5 \\
& 0.514 & \\
ethanol + acetonitrile & 0.189 & \\
& 1.722 & 0.6 \\
& 0.753 & \\
1-pentanol + acetonitrile & 0.379 & \\
& 3.164 & 0.6 \\
2-pentanol + acetonitrile & -0.545 & \\
& 0.956 & \\
& 3.449 & 0.6 \\
2-methyl-1-pentanol + acetonitrile & -0.265 & \\
& 3.659 & \\
& -0.727 & \\
& 1.074 & \\
4-methyl-2-pentanol + acetonitrile & 3.262 & 1.0 \\
& -0.622 & \\
& 1.825 &
\end{tabular}

a Combined NIBS/Redlich-Kister curve-fit parameters are ordered as $\mathrm{S}_{0}, \mathrm{~S}_{1}$ and $\mathrm{S}_{2} \cdot{ }^{\mathrm{b}}$ Deviation $(\%)=(100 / \mathrm{N}) \sum \mid\left[\left(\mathrm{x}_{\mathrm{A}}^{\text {sat }}\right)^{\text {calc }}-\right.$ $\left.\left(x_{A}^{\text {sat }}\right)^{\exp }\right] /\left(x_{A}^{\text {sat }}\right) \exp$.

mixture. ${ }^{10}$ More recently, Deng et al. ${ }^{11-13}$ and Pribyla et al. ${ }^{14-16}$ have shown that the $S_{i}$ coefficients determined by regressing experimental anthracene data in binary alkane + alkane, alkane + alcohol, alcohol + alcohol, alcohol + ether, and alkane + ether solvent mixtures allow one to predict anthracene solubilities in ternary alkane + alkane + alcohol, alkane + alcohol + alcohol, and alkane + alcohol + ether solvent mixtures. The predictive expression for the ternary solvent mixture is

$$
\begin{array}{r}
\ln x_{A}^{\text {sat }}=x_{B}^{\circ} \ln \left(x_{A}^{s a t}\right)_{B}+x_{C}^{\circ} \ln \left(x_{A}^{s a t}\right)_{C}+x_{D}^{\circ} \ln \left(x_{A}^{s a t}\right)_{D}+ \\
x_{B}^{\circ} x_{C}^{\circ} \sum_{i=0}^{r} S_{i, B C}\left(x_{B}^{\circ}-x_{C}^{\circ}\right)^{i}+x_{B}^{\circ} x_{D}^{\circ} \sum_{j=0}^{s} S_{j, B D}\left(x_{B}^{\circ}-x_{D}^{\circ}\right)^{j}+ \\
x_{C}^{\circ} x_{D}^{\circ} \sum_{k=0}^{t} S_{k, C D}\left(x_{C}^{\circ}-x_{D}^{\circ}\right)^{k}
\end{array}
$$

a mol efraction average of the logarithmic solute sol ubilities in the three pure solvents $\left[\left(x_{A}^{\text {sat }}\right)_{B},\left(x_{A}^{\text {sat }}\right)_{C}\right.$, and $\left.\left(x_{A}^{\text {sat }}\right)_{D}\right]$ plus a Redlich-Kister summation term for each solvent pair. The documented success ${ }^{11-16}$ of eq 3 in predicting anthracene solubilities in more than 60 different ternary solvent systems illustrates the need for measured solute sol ubilities in binary solvent mixtures.

The ability of eq 1 to mathematically represent the experimental solubility of anthracene in the six binary alcohol + acetonitrile mixtures is summarized in Table 2 in the form of "curve-fit" parameters and percent deviations in back-calculated solubilities. Each percent deviation is based upon the measured anthracene solubility data at the seven different binary solvent compositions. Careful examination of Table 2 reveals that eq 1 provided a fairly accurate mathematical representation for how the solubility of anthracene varies with solvent composition. Deviations between the experimental mole fraction solubilities and back-calculated values based upon eq 1 differed by an overall average absolute deviation of about $\pm 0.7 \%$, which is less than the experimental uncertainty. The mathematical correlations that have been developed correctly describe the maximum that is observed in each of the anthracene mole fraction solubility versus acetonitrile concentration solubility curves. 
722 J ournal of Chemical and Engineering Data, Vol. 48, No. 3, 2003

\section{Literature Cited}

(1) Acree, W. E., J r. Polycydic Aromatic Hydrocarbons in Pure and Binary Solvents; Volume 54 in IUPAC Solubility Data Series; Oxford University Press: Oxford, UK, 1994

(2) Acree, W. E., J r. Polycyclic Aromatic Hydrocarbons: Binary Nonaqueous Systems: Part 1 (Solutes A-E); Volume 58 In IUPAC Solubility Data Series; Oxford University Press: Oxford, UK, 1995.

(3) Acree, W. E., J r. Polycyclic Aromatic Hydrocarbons: Binary Nonaqueous Systems: Part 2 (Solutes F-Z); Volume 59 In IUPAC Solubility Data Series; Oxford University Press: Oxford, UK, 1995.

(4) Acree, W. E., J r. Mathematical Representation of Thermodynamic Properties. Part 2. Derivation of the Combined Nearly I deal Binary Solvent (NIBS)/Redlich-Kister Mathematical Representation from a Two-Body and Three-Body Interactional Mixing Model. Thermochim. Acta 1992, 198, 71-79.

(5) Acree, W. E., J r.; McCargar, J . W.; Zvaigzne, A. I.; Teng, I.-L. Mathematical Representation of Thermodynamic Properties. Carbazole Solubilities in Binary Alkane + Dibutyl Ether and Alkane + Tetrahydropyran Solvent Mixtures. Phys. Chem. Liq. 1991, 23, 27-35.

(6) Acree, W. E., J r.; Zvaigzne, A. I. Thermodynamic Properties of Nonelectrolyte Solutions. Part 4. Estimation and Mathematical Representation of Solute Activity Coefficients and Solubilities in Binary Solvents Using the NIBS and Modified Wilson Equation. Thermochim. Acta 1991, 178, 151-167.

(7) J ouyban-Gharamaleki, A.; Clark, B.J .; Acree, W. E., J r. Prediction of Drug Solubility in Ternary Solvent Mixture. Drug Dev. Ind. Pharm. 2000, 26, 971-973.

(8) J ouyban-Gharamaleki, A.; Acree, W. E., J r. Comparison of Models for Describing Multiple Peaks in Solubility Profiles. Int. J . Pharm 1998, 167, 177-182.
(9) J ouyban-Gharamaleki, A.; Hanaee, J. A Novel Method for Improvement of the CNIBS/R-K Equation. Int. J. Pharm. 1997, 154, 243-245.

(10) J ouyban-Gharamaleki, A.; Barzegar-J alali, M.; Acree, W. E., J r. Solubility Correlation of Structurally Related Drugs in Binary Solvent Mixtures. Int. J. Pharm. 1998, 166, 205-209.

(11) Dent, T.; Childress, S. D.; De Fina, K. M.; Sharp, T. L.; Acree, W. E., J r. Solubility of Anthracene in Ternary Propanol + Butanol $+2,2,4-T$ rimethylpentane Solvent Mixtures. J . Chem. Eng. Data 1998, 43, 1065-1067.

(12) Deng, T.; Childress, S. D.; De Fina, K. M.; Acree, W. E., J r. Solubility of Anthracene in Ternary Propanol + Butanol + Heptane Solvent Mixtures. Chem. Eng. Commun. 1999, 172, 217224.

(13) Deng, T. Thermodynamic Properties of Nonelectrolyte Solutes in Ternary Solvent Mixtures. Ph.D. Dissertation, University of North Texas, 1999.

(14) Pribyla, K. J .; Ezell, C.; Van, T. T.; Acree, W. E., J r. Solubility of Anthracene in Ternary Methyl tert-Butyl Ether + Alcohol + 2,2,4 Trimethylpentane Solvent Mixtures at 298.15 K. J . Chem. Eng Data 2000, 45, 974-976.

(15) Pribyla, K.J .; Chuca, I.; Van, T. T.; Acree, W. E., J r. Solubility of Anthracene in Ternary Methyl tert-Butyl Ether + Alcohol + Heptane Solvent Mixtures at 298.15 K. J . Chem. Eng. Data 2000, 45, 533- 535

(16) Pribyla, K. J. Thermochemical Study of Crystalline Solutes Dissolved in Ternary Hydrogen-Bonding Solvent Mixtures. Ph.D. Dissertation, University of North Texas, 2001.

Received for review November 26, 2002. Accepted February 26 2003. This research was supported in part by the University of North Texas Research Council.

J E020216B 